\title{
Learning disabilities and allergies among children and adolescents: are they linked?
}

\author{
Irene Rethemiotaki \\ Department of Production Engineering and Management, Technical University of Crete, Chania, Greece
}

\section{ABSTRACT}

Introduction: The main purpose of this work is to study the incidence of learning disabilities among children and adolescents during the period 2009-2018 in the United States and to find not only statistically significant predictors but also a possible association between learning disabilities and allergies.

Material and methods: The statistical methods used to derive the results of this work were the $\chi^{2}$ test and oneway analysis of variance (ANOVA), in order to check the statistical significance of learning disabilities in relation to socio-economic factors of children and adolescents. In addition, a multivariate logistic regression analysis was used with the odds ratio (OR) to find statistically significant prognostic factors for learning disabilities. The Pearson correlation coefficient was used to find the relationship between learning disabilities and allergies. Results: According to multiple logistic regression analysis, children and adolescents whose families are in a poor financial situation, family income less than $\$ 35,000$, and health insurance coverage "Medicaid" have two times higher risk of the occurrence of learning disabilities. In addition, children who have neither mother nor father also have higher risk for the occurrence of learning disabilities. Finally, a statistically significant relationship was found between the number of cases of learning disabilities and food allergies.

Conclusions: The results of this study describe for the first time the importance of deprivation (of family and financial comfort) as a primary prognostic risk factor for learning disabilities in children. It has also been found that not only deprivation but also death of the parents play a key role in the increased risk of developing these disorders. Moreover, a link has been found between learning disabilities and food allergies.

\section{KEY WORDS:}

prognostic factors, socioeconomic factors, learning disabilities, allergies.

\section{INTRODUCTION}

Learning disabilities (LD) are disorders in childhood, characterised by significant impairments in reading (dyslexia), writing (dysgraphia), and mathematics (dyscalculia) [1]. Difficulties in word recognition, reading comprehension, and inattention are some of the symptoms that the child is faced with $[2,3]$. The school grades of children with $\mathrm{LD}$ are observed to be low in spite of their normal intelligence (IQ greater than or equal to 90) and sensory abilities $[4,5]$. The prevalence of LD is approximately $14 \%$ among children and adolescents in the US [6]. Preterm birth, neonatal complications, language delay, and epilepsy are important risk factors for learning disabilities in children [7-9]. Moreover, home environment and family stresses, health risks, as well as socioeconomic status have also been reported [10].

Low socioeconomic status (SES) has been linked not only with poor physical health but also with mental health in childhood [11-19]. In particular, children from

\section{ADDRESS FOR CORRESPONDENCE:}

Irene Rethemiotaki, Department of Production Engineering and Management, Technical University of Crete, University Campus, 73100 Chania, Greece, ORCID: 0000-0001-5229-9946, e-mail: eirinireth@yahoo.gr 
low socioeconomic backgrounds are 1.18-3.34 times more likely to have mental health problems than their peers [19]. The association between LD and SES appears to be complex because symptoms are associated with interactions between genes and the environment during development [20]. Other factors that have been suggested as being responsible include maternal mental health [21], substance abuse [22], and the parent's involvement (or lack thereof) in raising their child [23].

Prior studies have found a positive association of allergies with learning disabilities [24, 25], but no clinical evidence of causation. Allergy is an adverse reaction caused by inhalants such as pollens and animal dandruff. Allergies, however, are caused not only by inhalation but also by food and chemicals present in the environment. Allergies affecting the brain can cause the child to have difficulty concentrating, easily detaching and eventually exhibiting unstable learning patterns. Allergies can be a major cause of a child's learning difficulties at school as they suffer from nasal impurity, watery eyes, fatigue, and headaches. For this purpose, this work studies learning disabilities and allergies in the United States in the period 2009-2018 in order to find statistically significant predictors for LD and a possible link between LD and allergies.

\section{MATERIAL AND METHODS}

The data used in this work come from the National Health Interview Survey (NHIS) dataset [26] and cover the period 2009-2018. The target population for NHIS is the civilian noninstitutionalised population of the United States. NHIS data are collected through personal household interviews. The main objective of NHIS is to monitor the health of the U.S. population through the collection and analysis of data on a broad range of health topics. Each year, a representative sample of households across the country is selected for NHIS using a multistage cluster sample design. Trained interviewers from the U.S. Census Bureau visits each selected household and administers the NHIS in person. To identify the children with learning difficulties, each household was asked to answer the following question: "Has a representative from a school or a health professional ever told you that [child's name] had a learning disability?". The total number of children examined was 617,012 , while the number of children and adolescents with LD was 47,548. Moreover, in the geographic classification of the U.S. population, states are grouped into four regions used by the U.S. Census Bureau:

- Northeast: Maine, Vermont, New Hampshire, Massachusetts, Connecticut, Rhode Island, New York, New Jersey, and Pennsylvania,

- Midwest: Ohio, Illinois, Indiana, Michigan, Wisconsin, Minnesota, Iowa, Missouri, North Dakota, South Dakota, Kansas, and Nebraska,
- South: Delaware, Maryland, District of Columbia, West Virginia, Virginia, Kentucky,

- Tennessee, North Carolina, South Carolina, Georgia, Florida, Alabama, Mississippi, Louisiana, Oklahoma, Arkansas, and Texas,

- West: Washington, Oregon, California, Nevada, New Mexico, Arizona, Idaho, Utah, Colorado, Montana, Wyoming, Alaska, and Hawaii.

The statistical methods used to extract the results of this work are the $\chi^{2}$ test for categorical and one-way analysis of variance (ANOVA) for continuous variables, in order to check the zero hypothesis that the average of children and adolescents in the United States with LD did not differ according to their socio-economic characteristics such as gender, age, race, origin, parent's education, family income, poverty status, health insurance coverage, current health status, family structure, place of residence, and region. Factors that determine the prevalence of $\mathrm{LD}$ were assessed by using multiple logistic regression analysis. To assess the predictors of $\mathrm{LD}$, data were used regarding children with a new diagnosis of LD compared to a matched cohort of children without LD. In particular, the control group was the group of children without LD with the same socioeconomic characteristics as the group of children with LD. Predictors were represented using the OR and $95 \%$ confidence intervals, and $p<0.05$ was considered statistically significant. More specifically, the odds ratio was used to determine whether a particular characteristic was a risk factor for learning disabilities, and to compare the magnitude of various risk factors for that outcome. An OR $>1$ means that the characteristic was associated with higher odds of outcome, and an OR $<1$ means that the characteristic was associated with lower odds of outcome. Pearson correlation coefficient was used for the relationship between LD and allergies for the period 2009-2018. The study was carried out using IBMSPSS 25 software package for Windows.

All procedures performed in studies involving human participants were in accordance with the ethical standards of the institutional and/or national research committee and with the 1964 Helsinki declaration and its later amendments or comparable ethical standards.

\section{RESULTS}

As shown in Table 1, there is a statistically significant difference in the number of LD children in relation both to gender and age, occurring mainly in males $(63.2 \%)$ in the age group $12-17$ years $(50.4 \%)$, while the most common origin and race are White $(79.1 \%)$ and not Hispanic or Latino (42.1\%). Most children with learning disabilities have parents with more than a high school diploma $(62.1 \%)$ and excellent or very good current health status (63\%). Moreover, most families whose children have LD are not poor $(43.6 \%)$, with a family income of $\$ 35,000$ or more $(36.2 \%)$ and Medicaid health insurance coverage 
TABLE 1. Results of $\chi^{2}$ and one-way ANOVA test

\begin{tabular}{|c|c|c|c|}
\hline Characteristics & Number of children with LD & Percentages & $p$-value \\
\hline \multicolumn{3}{|l|}{ Gender } & \multirow[t]{3}{*}{$<0.001$} \\
\hline Male & 30,061 & 63.2 & \\
\hline Female & 17,487 & 36.8 & \\
\hline \multicolumn{3}{|l|}{ Age } & \multirow[t]{4}{*}{$<0.001$} \\
\hline $3-4$ & 2,420 & 5.1 & \\
\hline $5-11$ & 21,177 & 44.5 & \\
\hline $12-17$ & 23,952 & 50.4 & \\
\hline \multicolumn{3}{|l|}{ Race } & \multirow[t]{4}{*}{$<0.001$} \\
\hline White & 35,111 & 79.1 & \\
\hline Black or African American & 8,267 & 18.6 & \\
\hline Asian & 983 & 2.2 & \\
\hline \multicolumn{3}{|l|}{ Origin } & \multirow[t]{6}{*}{$<0.001$} \\
\hline Hispanic or Latino & 10,570 & 12 & \\
\hline Mexican or Mexican American & 6,607 & 7.5 & \\
\hline Not Hispanic or Latino & 36,980 & 42.1 & \\
\hline White, single race & 25,984 & 29.6 & \\
\hline Black or African American, single race & 7,676 & 8.7 & \\
\hline \multicolumn{3}{|l|}{ Parents' education } & \multirow[t]{4}{*}{$<0.001$} \\
\hline Less than a high school diploma & 6,940 & 15.4 & \\
\hline High school diploma & 10,157 & 22.5 & \\
\hline More than a high school diploma & 27,965 & 62.1 & \\
\hline \multicolumn{3}{|l|}{ Family income } & \multirow[t]{7}{*}{$<0.001$} \\
\hline Less than $\$ 35,000$ & 19,318 & 27.6 & \\
\hline$\$ 35,000$ or more & 25,353 & 36.2 & \\
\hline$\$ 35,000-\$ 49,999$ & 5,531 & 7.9 & \\
\hline$\$ 50,000-\$ 74,999$ & 6,975 & 10.0 & \\
\hline$\$ 75,000-\$ 99,999$ & 4,388 & 6.3 & \\
\hline$\$ 100,000$ or more & 8,460 & 12.1 & \\
\hline \multicolumn{3}{|l|}{ Poverty status } & \multirow[t]{4}{*}{$<0.001$} \\
\hline Poor & 13,435 & 29.5 & \\
\hline Near poor & 12,209 & 26.8 & \\
\hline Not poor & 19,864 & 43.6 & \\
\hline \multicolumn{3}{|l|}{ Health insurance coverage } & \multirow[t]{5}{*}{$<0.001$} \\
\hline Private & 19,597 & 41.5 & \\
\hline Medicaid & 23,999 & 50.8 & \\
\hline Other coverage & 1,154 & 2.4 & \\
\hline Uninsured & 2,526 & 5.3 & \\
\hline \multicolumn{3}{|l|}{ Current health status } & \multirow[t]{4}{*}{$<0.001$} \\
\hline Excellent or very good & 29,937 & 63.0 & \\
\hline Good & 13,196 & 27.8 & \\
\hline Fair or poor & 4,401 & 9.3 & \\
\hline
\end{tabular}


TABLE 1. Cont

\begin{tabular}{|c|c|c|c|}
\hline Characteristics & Number of children with LD & Percentages & $p$-value \\
\hline \multicolumn{3}{|l|}{ Family structure } & \multirow[t]{5}{*}{$<0.001$} \\
\hline Mother and father & 26,828 & 56.4 & \\
\hline Mother, no father & 16,317 & 34.3 & \\
\hline Father, no mother & 2,006 & 4.2 & \\
\hline Neither mother nor father & 2,396 & 5.0 & \\
\hline \multicolumn{3}{|l|}{ Place of residence } & \multirow[t]{4}{*}{$<0.001$} \\
\hline Large MSA (population size 1 million or more) & 24,738 & 52.0 & \\
\hline Small MSA (less than 1 million) & 15,130 & 31.8 & \\
\hline Not in MSA & 7,681 & 16.2 & \\
\hline \multicolumn{3}{|l|}{ Region } & \multirow[t]{5}{*}{$<0.001$} \\
\hline Northeast & 8,895 & 18.7 & \\
\hline Midwest & 10,835 & 22.8 & \\
\hline South & 17,719 & 37.3 & \\
\hline West & 10,102 & 21.2 & \\
\hline
\end{tabular}

$L D$ - learning disabilities, MSA - metropolitan statistical area

(50.8\%). In addition, most children with LD have both mother and father as a family structure (56.4\%). Finally, the region with the most frequent occurrence of $L D$ was the south $(37.3 \%)$, with a population size of one million or more $(52.0 \%)$.

Table 2 shows the multiple logistic regression analysis and odds ratios in order to find the predictors of the occurrence of LD. As shown in Table 2, all prognostic factors are statistically significant $(p<0.05)$. According to multiple logistic regression, the risk of LD is significantly higher with male gender (odds ratio [OR 1.71], age 12-17 years old [OR 1.0], Black or African American race [OR 3.0], and "Less than a high school diploma" parents' education status [OR 1.5]). In addition, the risk of LD is significantly higher with family income less than $\$ 35,000$ (OR 2.3), poverty status "poor" (OR 2.0), health insurance coverage "Medicaid" (OR 1.8), and current health status "Fair or poor" (OR 1.0). Children who have neither mother nor father have almost two times higher risk for the occurrence of $L D(O R$ 1.5). Finally, the risk of LD is significantly higher in the region "Northeast" (OR 1.3) and place of residence "not in a metropolitan statisti$\mathrm{cal}$ area" (OR 1.0). Figure 1 shows the trend in both LD and allergies during the period 2009-2018 in the United States. There is an increasing trend in the appearance of $\mathrm{LD}$, and food and skin allergies but a decreasing trend in the appearance of respiratory allergies.

Table 3 shows the Pearson correlation coefficient among the total number of LD and allergic patients for the years 2009 to 2018 . The type of allergies that have been examined were food, respiratory, and skin allergies. As can be seen in Table 3, the incidence of learning disabilities is statistically significantly associated only with food allergies $(p<0.05)$. The Pearson correlation coef- ficient between the total number of LD and allergic patients is 0.58 , which indicates that there is a correlation between $\mathrm{LD}$ and food allergies.

In order to confirm the link between $\mathrm{LD}$ and food allergies, a multivariate logistic regression analysis was also used for children with food allergies. As can be seen in Table 4, family structure plays a crucial role in the incidence of food allergies. In particular, children who have neither mother nor father have the highest risk for the occurrence of this type of allergy (OR 1.29). Moreover, the risk of food allergies is significantly higher with male gender (OR 1.03), age 12-17 years (OR 1.0), Black or African American race (OR 1.03), and fair or poor current health status (OR 1.0). Children whose families have more than a high school education status (OR 1.0), who are not poor (OR 1.0), and whose health insurance coverage neither was private or Medicaid (OR 1.42) also have an increased risk of having food allergies. Finally, the risk of food allergies is significantly higher in the region "Northeast" (OR 1.08) and place of residence "Small MSA" (OR 1.18).

Figure 2 represents the prognostic risk factors with the odds ratios for LD in children. As can be seen, race, family income, and family structure play a crucial role in LD, while these children are two-fold more likely to be males.

\section{DISCUSSION}

Increasing attention should be given to the prognostic factors that have the highest odds ratio. It is noteworthy that children whose families are in a poor financial situation are twice as likely to have learning disabilities. Moreover, family structure plays a crucial role in the incidence of LD. Children who have neither mother nor fa- 
TABLE 2. Statistically significant predictors of learning disabilities in children using multivariate logistic regression

\begin{tabular}{|c|c|c|c|c|}
\hline Characteristics & Children with LD & Controls & Odds ratio $(95 \% \mathrm{CI})$ & $p$-value \\
\hline \multicolumn{4}{|l|}{ Gender } & \multirow[t]{3}{*}{$<0.001$} \\
\hline Male & 30,061 & 285,295 & $1.71(1.67-1.74)$ & \\
\hline Female & 17,487 & 284,169 & 1.00 & \\
\hline \multicolumn{4}{|l|}{ Age } & \multirow[t]{4}{*}{$<0.001$} \\
\hline $3-4$ & 2,420 & 80,824 & $0.28(0.26-0.29)$ & \\
\hline $5-11$ & 21,177 & 266,059 & $0.74(0.72-0.75)$ & \\
\hline $12-17$ & 23,952 & 223,745 & 1.00 & \\
\hline \multicolumn{4}{|l|}{ Race } & \multirow[t]{4}{*}{$<0.001$} \\
\hline White & 35,111 & 424,057 & $2.5(2.3-2.7)$ & \\
\hline Black or African American & 8,267 & 82,913 & $3.0(2.8-3.2)$ & \\
\hline Asian & 983 & 30,201 & 1.00 & \\
\hline \multicolumn{4}{|l|}{ Origin } & \multirow[t]{6}{*}{$<0.001$} \\
\hline Hispanic or Latino & 10,570 & 136,434 & $0.78(0.75-0.8)$ & \\
\hline Mexican or Mexican American & 6,607 & 92,513 & $0.71(0.69-0.74)$ & \\
\hline Not Hispanic or Latino & 36,980 & 434,196 & $0.85(0.83-0.88)$ & \\
\hline White, single race & 25,984 & 302,728 & $0.86(0.84-0.88)$ & \\
\hline Black or African American, single race & 7,676 & 77,259 & 1.00 & \\
\hline \multicolumn{4}{|l|}{ Parents' education } & \multirow[t]{4}{*}{$<0.001$} \\
\hline Less than a high school diploma & 6,940 & 63,908 & $1.5(1.4-1.5)$ & \\
\hline High school diploma & 10,157 & 101,156 & $1.4(1.3-1.4)$ & \\
\hline More than a high school diploma & 27,965 & Z385,959 & 1.00 & \\
\hline \multicolumn{4}{|l|}{ Family income } & \multirow[t]{7}{*}{$<0.001$} \\
\hline Less than $\$ 35.000$ & 19,318 & 153,275 & $2.3(2.2-2.3)$ & \\
\hline$\$ 35,000$ or more & 25,353 & 373,386 & $1.23(1.2-1.26)$ & \\
\hline$\$ 35,000-\$ 49,999$ & 5,531 & 64,804 & $1.6(1.5-1.6)$ & \\
\hline$\$ 50,000-\$ 74,999$ & 6,975 & 88,497 & $1.3(1.4-1.5)$ & \\
\hline$\$ 75,000-\$ 99,999$ & 4,388 & 66,734 & $1.2(1.14-1.23)$ & \\
\hline$\$ 100,000$ or more & 8,460 & 153,354 & 1.00 & \\
\hline \multicolumn{4}{|l|}{ Poverty status } & \multirow[t]{4}{*}{$<0.001$} \\
\hline Poor & 13,435 & 103,107 & $2.0(2.0-2.1)$ & \\
\hline Near poor & 12,209 & 120,563 & $1.6(1.6-1.7)$ & \\
\hline Not poor & 19,864 & 313,776 & 1.00 & \\
\hline \multicolumn{4}{|l|}{ Health insurance coverage } & \multirow[t]{5}{*}{$<0.001$} \\
\hline Private & 19,597 & 320,083 & $0.9(0.8-0.9)$ & \\
\hline Medicaid & 23,999 & 195,893 & $1.8(1.7-1.9)$ & \\
\hline Other coverage & 1,154 & 15,287 & $1.1(1.0-1.2)$ & \\
\hline Uninsured & 2,526 & 37,192 & 1.00 & \\
\hline \multicolumn{4}{|l|}{ Current health status } & \multirow[t]{4}{*}{$<0.001$} \\
\hline Excellent or very good & 29,937 & 485,316 & $0.11(0.10-0.11)$ & \\
\hline Good & 13,196 & 77,331 & $0.30(0.29-0.31)$ & \\
\hline Fair or poor & 4,401 & 7,899 & 1.00 & \\
\hline
\end{tabular}


TABLE 2. Cont.

\begin{tabular}{|c|c|c|c|c|}
\hline Characteristics & Children with LD & Controls & Odds ratio $(95 \%$ CI) & $p$-value \\
\hline \multicolumn{4}{|l|}{ Family structure } & \multirow[t]{5}{*}{$<0.001$} \\
\hline Neither mother nor father & 26,828 & 396,020 & $1.5(1.4-1.6)$ & \\
\hline Mother, no father & 16,317 & 134,129 & $0.76(0.72-0.8)$ & \\
\hline Father, no mother & 2,006 & 22,620 & $1.3(1.3-1.4)$ & \\
\hline Mother and father & 2,396 & 17,866 & 1.00 & \\
\hline \multicolumn{4}{|l|}{ Place of residence } & \multirow[t]{4}{*}{$<0.001$} \\
\hline Large MSA (population size 1 million or more) & 24,738 & 313,870 & $0.75(0.73-0.77)$ & \\
\hline Small MSA (less than 1 million) & 15,130 & 159,785 & $0.9(0.8-0.9)$ & \\
\hline Not in MSA & 7,681 & 73,310 & 1.00 & \\
\hline \multicolumn{4}{|l|}{ Region } & \multirow[t]{5}{*}{$<0.001$} \\
\hline Northeast & 8,895 & 92,041 & $1.3(1.3-1.4)$ & \\
\hline Midwest & 10,835 & 128,938 & $1.1(1.1-1.2)$ & \\
\hline South & 17,719 & 211,029 & $1.1(1.1-1.2)$ & \\
\hline West & 10,102 & 138,623 & 1.00 & \\
\hline
\end{tabular}

$L D$ - learning disabilities, MSA - metropolitan statistical area

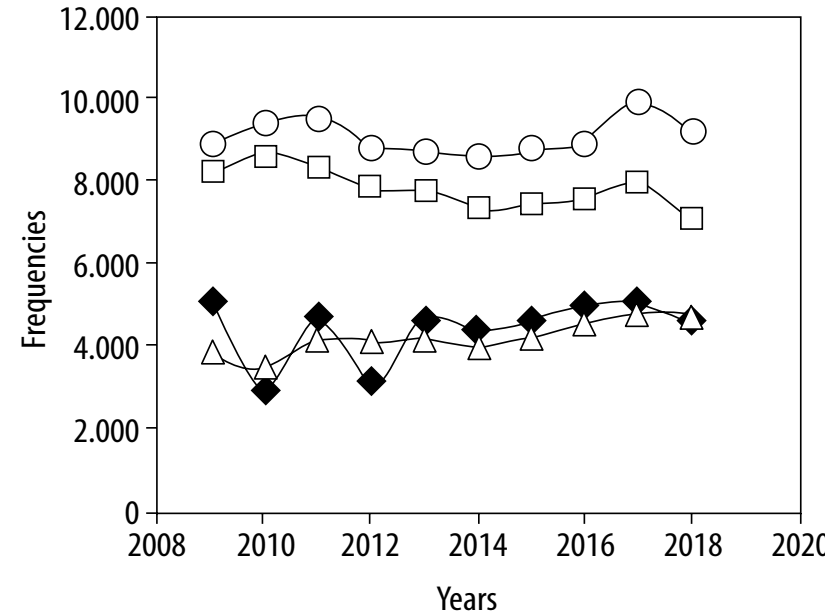

$\neg$ Learning disabilities $\quad \square-$ Respiratory allergies

$\triangle$ Food allergies $\quad-O$ - Skin allergies

FIGURE 1. The trend in learning disabilities and allergies during the period 2009-2018 in the United States

ther have almost two times higher risk for the occurrence of LD. This can be explained by the fact that the complete lack of parents reflects problems in the psychopathology of the child. However, when combining the higher risk of children in low-income families, the complete lack of parents probably reflects the financial distress faced by these children.

It is also noteworthy that the socio-economic characteristics of children with learning disabilities with the highest odds ratio were the same as those of children with food allergies. Males, 12-17 years old, of Black or African American race are at greater risk for the occurrence of both learning disabilities and food allergies.
TABLE 3. Pearson correlation coefficient for the relationship between learning disabilities and allergies

\begin{tabular}{|l|c|c|}
\hline Factor & Pearson correlation $r$ & $p$-value \\
\hline Learning disabilities & 1 & \\
\hline Food allergies & 0.58 & $<0.05$ \\
\hline Respiratory allergies & -0.30 & $>0.05$ \\
\hline Skin allergies & 0.07 & $>0.05$ \\
\hline
\end{tabular}

Deprivation of family proved to be the primary prognostic risk factor for both LD and food allergies, a fact that implies a possible link between LD and food allergies. One possible explanation is the presence of shared mechanisms among these allergic conditions in relation to learning disabilities. Allergic disease is caused by an acute immunological response that involves mast cells, basophils, and eosinophil activation by allergens cross-linking with immunoglobulin E ( IgE) [27]. It then releases histamine and other inflammatory mediators such as cytokines or the eosinophil response [28]. The imbalance between inflammatory mediators and their compensatory molecules may affect central nervous system homeostasis, which may result in neurological disorders or possible LD development in the affected child [29]. Prior studies have been identified allergies as a barrier to learning [30]. It is of the utmost importance to acknowledge the seriousness of learning disabilities in children, which in return reflects the responsibility of underlying diseases such as allergies.

One limitation of the present study is that data were collected through personal household interviews. Non-disclosure such a disability by participants is possible. 
TABLE 4. Statistically significant predictors of food allergies in children, using multivariate logistic regression

\begin{tabular}{|c|c|c|c|c|}
\hline Characteristics & Children with food allergies & Controls & Odds ratio $(95 \% \mathrm{CI})$ & $p$-value \\
\hline \multicolumn{4}{|l|}{ Gender } & \multirow[t]{3}{*}{$<0.001$} \\
\hline Male & 21,708 & 355,031 & $1.03(1.01-1.05)$ & \\
\hline Female & 20,177 & 340,653 & 1.00 & \\
\hline \multicolumn{4}{|l|}{ Age } & \multirow[t]{4}{*}{$<0.001$} \\
\hline $3-4$ & 11,473 & 191,286 & $1.01(0.98-1.03)$ & \\
\hline $5-11$ & 16,544 & 270,692 & $1.00(1.00-1.05)$ & \\
\hline $12-17$ & 13,870 & 233,827 & 1.00 & \\
\hline \multicolumn{4}{|l|}{ Race } & \multirow[t]{4}{*}{$<0.001$} \\
\hline White & 29,615 & 517,644 & $0.90(0.86-0.94)$ & \\
\hline Black or African American & 6,683 & 101,878 & $1.03(0.98-1.09)$ & \\
\hline Asian & 2,184 & 34,557 & 1.00 & \\
\hline \multicolumn{4}{|l|}{ Origin } & \multirow[t]{6}{*}{$<0.001$} \\
\hline Hispanic or Latino & 8,035 & 170,117 & $0.72(0.70-0.74)$ & \\
\hline Mexican or Mexican American & 4,662 & 114,996 & $0.62(0.59-0.64)$ & \\
\hline Not Hispanic or Latino & 33,850 & 525,695 & $0.98(0.96-1.01)$ & \\
\hline White, single race & 22,897 & 366,809 & $0.95(0.92-0.98)$ & \\
\hline Black or African American, single race & 6,167 & 94,526 & 1.00 & \\
\hline \multicolumn{4}{|l|}{ Parents' education } & \multirow[t]{4}{*}{$<0.001$} \\
\hline Less than a high school diploma & 7,386 & 77,344 & $0.55(0.53-0.58)$ & \\
\hline High school diploma & 13,269 & 121,150 & $0.69(0.67-0.71)$ & \\
\hline More than a high school diploma & 40,674 & 452,985 & 1.00 & \\
\hline \multicolumn{4}{|l|}{ Family income } & \multirow[t]{7}{*}{$<0.001$} \\
\hline Less than $\$ 35,000$ & 11,380 & 199,848 & $0.81(0.79-0.83)$ & \\
\hline$\$ 35,000$ or more & 27,981 & 443,721 & $0.90(0.88-0.92)$ & \\
\hline$\$ 35,000-\$ 49,999$ & 4,831 & 79,451 & $0.87(0.84-0.90)$ & \\
\hline$\$ 50,000-\$ 74,999$ & 5,992 & 108,535 & $0.79(0.76-0.81)$ & \\
\hline$\$ 75,000-\$ 99,999$ & 4,880 & 80,030 & $0.87(0.84-0.90)$ & \\
\hline$\$ 100,000$ or more & 12,276 & 175,706 & 1.00 & \\
\hline \multicolumn{4}{|l|}{ Poverty status } & \multirow[t]{4}{*}{$<0.001$} \\
\hline Poor & 7,488 & 136,426 & $0.85(0.83-0.87)$ & \\
\hline Near poor & 8,776 & 149,118 & $0.91(0.89-0.94)$ & \\
\hline Not poor & 23,789 & 370,373 & 1.00 & \\
\hline \multicolumn{4}{|l|}{ Health insurance coverage } & \multirow[t]{5}{*}{$<0.001$} \\
\hline Private & 24,281 & 374,446 & $1.29(1.23-1.35)$ & \\
\hline Medicaid & 13,928 & 257,391 & $1.08(1.03-1.13)$ & \\
\hline Other coverage & 1,337 & 18,668 & $1.42(1.33-1.53)$ & \\
\hline Uninsured & 2,140 & 42,694 & 1.00 & \\
\hline \multicolumn{4}{|l|}{ Current health status } & \multirow[t]{4}{*}{$<0.001$} \\
\hline Excellent or very good & 32,258 & 587,531 & $0.29(0.28-0.31)$ & \\
\hline Good & 7,451 & 96,404 & $0.41(0.39-0.48)$ & \\
\hline Fair or poor & 2,178 & 11,757 & 1.00 & \\
\hline
\end{tabular}


TABLE 4. Cont.

\begin{tabular}{|c|c|c|c|c|}
\hline Characteristics & Children with food allergies & Controls & Odds ratio $(95 \% \mathrm{CI})$ & $p$-value \\
\hline \multicolumn{4}{|l|}{ Family structure } & \multirow[t]{5}{*}{$<0.001$} \\
\hline Neither mother nor father & 1,069 & 21,712 & $1.29(1.20-1.39)$ & \\
\hline Mother, no father & 10,498 & 164,258 & $1.28(1.21-1.38)$ & \\
\hline Father, no mother & 994 & 25,728 & $0.78(0.71-0.85)$ & \\
\hline Mother and father & 29,327 & 484,111 & 1.00 & \\
\hline \multicolumn{4}{|l|}{ Place of residence } & \multirow[t]{4}{*}{$<0.001$} \\
\hline Large MSA (population size 1 million or more) & 23,081 & 379,924 & $1.14(1.11-1.18)$ & \\
\hline Small MSA (less than 1 million) & 13,539 & 216,301 & $1.18(1.14-1.22)$ & \\
\hline Not in MSA & 5,267 & 99,583 & 1.00 & \\
\hline \multicolumn{4}{|l|}{ Region } & \multirow[t]{5}{*}{$<0.001$} \\
\hline Northeast & 7,431 & 112,051 & $1.08(1.04-1.11)$ & \\
\hline Midwest & 9,069 & 157,643 & $0.93(0.91-0.96)$ & \\
\hline South & 15,087 & 258,348 & $0.95(0.92-0.97)$ & \\
\hline West & 10,298 & 167,771 & 1.00 & \\
\hline
\end{tabular}

MSA - metropolitan statistical area

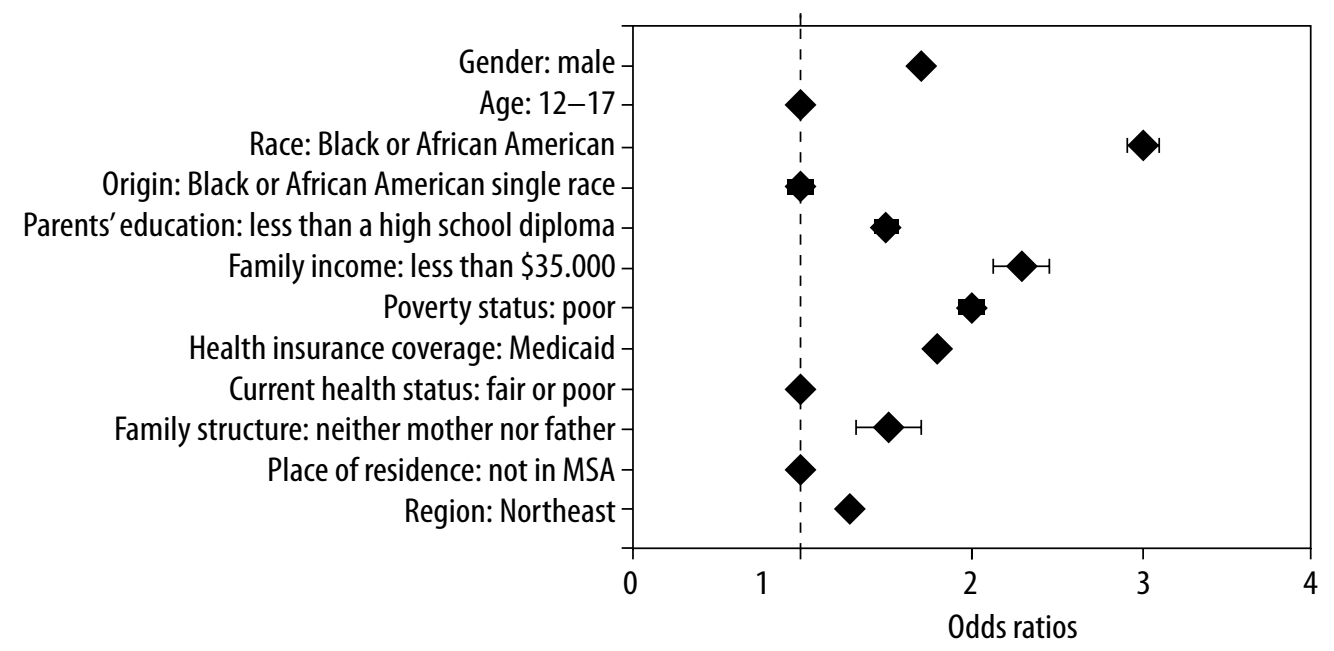

FIGURE 2. Prognostic risk factors with the odds ratios for learning disabilities in children during the period 2009-2018 in the United States

\section{CONCLUSIONS}

The importance of this study lies in the association of multiple socio-economic variables with learning disabilities in children 12-17 years old. More specifically, it was found that deprivation of the parents' financial security and education rapidly increases the risk of LD. It was also found that not only deprivation but also the death of parents plays a key role in the increased risk of developing these disorders. Moreover a link was found between learning disabilities and food allergies.

\section{DISCLOSURE}

The author declares no conflict of interest.

\section{REFERENCES}

1. Karande S, Kulkarni M. Specific learning disability: The invisible handicap. Indian Pediatr 2005; 42: 315-319.

2. Demonet JF, Taylor MJ, Chaix Y. Developmental dyslexia. Lancet 2004; 363: 1451-1460.

3. Billard C1, Delteil-Pinton F. Dyslexia: clinical characteristics. Arch Pediatr 2010; 17: 1734-1743.

4. Shapiro BK, Gallico RP. Learning disabilities. Pediatr Clin North Am 1993; 40: 491-505.

5. Agarwal KN, Agarwal DK, Upadhyay SK, et al. Learning disability in rural primary school children. Indian J Med Res 1991; 94: 89-95.

6. Zablotsky B, Alford JM. Racial and ethnic differences in the prevalence of attention-deficit/hyperactivity disorder and learning disabilities among U.S. children aged 3-17 years. NCHS Data Brief, no 358. National Center for Health Statistics, Hyattsville, MD 2020. 
7. Vega YH, Smith A, Cockerill H, et al. Risk factors for reading disability in families with rolandic epilepsy. Epilepsy Behav 2015; 53: 174-179.

8. Taylor HG, Espy KA, Anderson PJ. Mathematics deficiencies in children with very low birth weight or very preterm birth. Dev Disabil Res Rev 2009; 15: 52-59.

9. Jaekel J, Wolke D. Preterm birth and dyscalculia. J Pediatr 2014; 164: 1327-1332.

10. Dilnot J, Hamilton L, Maughan B, et al. Child and environmental risk factors predicting readiness for learning in children at high risk of dyslexia. Dev Psychopathol 2017; 29: 235-244.

11. Spencer N. Poverty and child health. Radcliffe Medical Press Ltd., 2000.

12. Schneiders J, Drukker M, van der Ende J, et al. Neighbourhood socioeconomic disadvantage and behavioural problems from late childhood into early adolescence. J Epidemiol Community Health 2003; 57: 699-703.

13. Kalff AC, Kroes M, Vles JS, et al. Neighbourhood level and individual level SES effects on child problem behaviour: a multilevel analysis. J Epidemiol Community Health 2001; 55: 246-250.

14. Boe T, Overland S, Lundervold AJ, Hysing M. Socioeconomic status and children's mental health: results from the Bergen Child Study. Soc Psychiatry Psychiatr Epidemiol 2012; 47: 1557-1566.

15. Keyes KM, March D, Link BG, et al. Do socio-economic gradients in smoking emerge differently across time by gender? Implications for the tobacco epidemic from a pregnancy cohort in California, USA. Soc Sci Med 2013; 76: 101-106.

16. Graham H. Building an inter-disciplinary science of health inequalities: the example of lifecourse research. Soc Sci Med 2002; 55: 2005-2016.

17. Aber JL, Bennett NG, Conley DC, et al. The effects of poverty on child health and development. Annu Rev Public Health 1997; 18 463-483.

18. Kiernan KE, Mensah FK. Poverty, maternal depression, family status and children's cognitive and behavioural development in early childhood: A longitudinal study. J Soc Policy 2009; 38: 569-588.

19. Reiss F. Socioeconomic inequalities and mental health problems in children and adolescents: A systematic review. Soc Sci Med 2013; 90: 24-31.

20. Russell G, Ford T, Rosenberg R, et al. The association of attention deficit hyperactivity disorder with socioeconomic disadvantage: alternative explanations and evidence. J Child Psychol Psychiatry 2014; 55: 436-445.

21. Sagiv SK, Epstein JN, Bellinger DC, et al. Pre- and postnatal risk factors for ADHD in a nonclinical pediatric population. J Atten Disord 2013; 17: 47-57.

22. Lingineni RK, Biswa S, Ahmad N, et al. Factors associated with attention deficit/hyperactivity disorder among US children: Results from a national survey. BMC Pediatrics 2012; 12: 50.

23. Gonzalez-DeHass AR, Willems PP, Holbein MFD. Examining the relationship between parental involvement and student motivation. Educ Psychol Rev 2005; 17: 99-123.

24. Tryphonas H, Trites RL. Food allergy in children with hyperactivity, learning disabilities and/or minimal brain dysfunction. Ann Allergy $1979 ; 42: 22-27$.

25. Wang J, Bingemann T, Russell AF, et al. The allergist's role in anaphylaxis and food allergy management in the school and childcare setting. J Allergy Clin Immunol Pract 2018; 6: 427-435.

26. National Center for Health Statistics. Data file documentation, National Health Interview Survey, 2016. Available from: https:// www.cdc.gov/nchs/nhis.htm.

27. Gould HJ, Sutton BJ, Beavil AJ, et al. The biology of IgE and the basis of allergic disease. Ann Rev Immunol 2003; 21: 579-628.
28. Corry DB, Kheradmand F. Induction and regulation of the IgE response. Nature 1999; 402 (6760 Suppl): B18-23.

29. Basso AS, Costa Pinto FA, Russo M, et al. Neural correlates of IgE-mediated food allergy. J Neuroimmunol 2003; 140: 69-77.

30. Levin ME, van Niekerk A, Katz H, et al. Allergies in schools. Curr Allergy Clin Immunol 2016; 29: 272-276. 